\title{
Letter to the Article by Maus et al.: "Order of Treatment Matters in Ischemic Stroke: Mechanical Thrombectomy First, Then Carotid Artery Stenting for Tandem Lesions of the Anterior Circulation"
}

\author{
Hongchen Zhao \\ Department of Neurology, Huashan Hospital, Shanghai, China
}

Maus et al. [1] concluded that mechanical thrombectomy prior to acute CAS in tandem occlusion was a predictive factor for favorable clinical outcome at 90 days due to a significantly higher rate of successful reperfusion (92 vs. 56\%). In this retrospective case-control study, baseline characteristics were similar between "antegrade" and "retrograde" groups.

However, the distribution of stenosis severity at baseline of 2 groups was not described. In case of severe chronic stenosis, an aspiration catheter might be unable to pass through the lesion. Therefore, it seemed that patients with most severe stenosis lesion would most probably be treated in the "antegrade" group, and this impact factor could be different between 2 groups.

Furthermore, during the thrombectomy procedure, especially in the patients

\section{References}

1 Maus V, Borggrefe J, Behme D, et al: Order of treatment matters in ischemic stroke: mechanical thrombectomy first, then carotid artery stenting for tandem lesions of the anterior circulation. Cerebrovasc Dis 2018;46: 59-65.

2 Oh JS, Yoon SM, Shim JJ, et al: Efficacy of balloon-guiding catheter for mechanical thrombectomy in patients with anterior circulation treated with retrieved stent, the application of a proximal prevention device, such as balloon guiding catheter, was not mentioned in the study. Previous studies [2-4] and meta-analyses [5] indicated that balloon guide catheter could significantly improve successful recanalization rate as well as efficiency in patients with anterior circulation ischemic stroke. It was suggested that antegrade flow arrest caused by balloon guide catheter might reduce the migration of the entrapped thrombus or fragmented clots extracted by the stent retriever. However, in the "retrograde" group, untreated proximal lesions may imitate the flow arrest effect. Thus, such difference between groups may play an important role in the recanalization procedure and the prognosis of patients with anterior circulation ischemic stroke.
I appreciate the guidance received from Maus; it helped me clarify the doubts referred to above. Thanks for your concern.

\section{Acknowledgment}

None.

\section{Disclosure Statement}

The authors have no conflicts of interest to declare.

\section{Funding Source}

None. ischemic stroke. J Korean Neurosurg Soc 2017;60:155-164.

3 Velasco A, Buerke B, Stracke CP, et al: Comparison of a balloon guide catheter and a non-balloon guide catheter for mechanical thrombectomy. Radiology 2016;280:169176 .

4 Nguyen TN, Malisch T, Castonguay AC, et al: Balloon guide catheter improves revascular- ization and clinical outcomes with the solitaire device: analysis of the north american solitaire acute stroke registry. Stroke 2014;45: 141-145.

5 Brinjikji W, Starke RM, Murad MH, et al: Impact of balloon guide catheter on technical and clinical outcomes: a systematic review and meta-analysis. J Neurointerv Surg 2018; 10:335-339.

\section{KARGER}

(c) 2018 S. Karger AG, Basel

E-Mail karger@karger.com

www.karger.com/ced
Hongchen Zhao

Department of Neurology, Huashan Hospital

14th Floor, Tower 2, No. 12 Middle Wulumuqi Road

Shanghai 200040 (China)

E-Mail 17111220024@fudan.edu.cn 